\title{
Daratumumab and venetoclax in combination with chemotherapy provide sustained molecular remission in relapsed/ refractory CD19, CD20, and CD22 negative acute $B$ lymphoblastic leukemia with KMT2A-AFF1 transcript
}

Sophie Voruz ${ }^{1,2^{*}}$, Sabine Blum ${ }^{1,3}$, Laurence de Leval ${ }^{4}$, Jacqueline Schoumans ${ }^{5}$, Françoise Solly ${ }^{1}$ and Olivier Spertini $i^{1,2,3^{*}}$

\begin{abstract}
Relapsed/refractory (R/R) B-cell acute lymphoblastic leukemia (B-ALL) has a very poor prognosis with a median overall survival of four to nine months. Achieving a complete molecular response is most often required to obtain a sustained leukemia-free survival after allogeneic hematopoietic stem cell transplantation. Immunotherapies targeting CD19, CD20, or CD22 are very efficient in achieving this goal. However, in the absence of the expression of these immunotherapeutic targets by lymphoblasts, treatment options are extremely scarce. We report the successful treatment of a 26-year-old man who suffered R/R, CD19, CD20, and CD22 negative B-ALL targeting BCl-2 and CD38 by combining venetoclax and daratumumab with chemotherapy.

Keywords: Relapsed/refractory B-cell precursor acute lymphoblastic leukemia, Adult B-cell lymphoma/leukemia, Targeted treatment, Chemotherapy regimen, Daratumumab, CD38, venetoclax, Bcl-2, Refractory disease,

Immunotherapies
\end{abstract}

To the editor.

Patients with R/R B-ALL have unmet clinical needs $[1,2]$. Achieving a complete molecular response is most often required to obtain a sustained leukemia-free survival after allogeneic hematopoietic stem cell transplantation (ASCT). Immunotherapies targeting $\mathrm{CD} 19$ or $\mathrm{CD} 22$ are very efficient in achieving this goal. However, B-ALL may escape targeted therapies by developing $\mathrm{CD} 19$ or $\mathrm{CD} 22$ negative blast cells

\footnotetext{
*Correspondence: sophie.voruz@chuv.ch; olivier.spertini@chuv.ch

'Service and Central Laboratory of Hematology, Lausanne University Hospital (CHUV), Lausanne, Switzerland

Full list of author information is available at the end of the article
}

and/or by switching to a mixed myeloid and lymphoid phenotype.

A 26-year-old man presented with asthenia and fever. The white blood cell count was $121 \mathrm{G} / \mathrm{l}$, hemoglobin $65 \mathrm{~g} /$ l, and platelets $44 \mathrm{G} / 1$. $95 \%$ of bone marrow cellularity was infiltrated by a pro-B ALL that was positive for CD34, HLA-DR, CD19, CD38, TdT, BCL-2, partially CD79a, and negative for $\mathrm{CD} 10, \mathrm{CD} 123$, cytoplasmic IgM and cytoplasmic CD3. Conventional karyotype was normal (46,XY). Polymerase chain reaction (PCR) and fluorescence in situ hybridization detected a KMT2A-AFF1 fusion gene transcript. The ALL was treated according to the GRAALL- 
2005 induction protocol [3]. A morphologic complete remission (CR) was achieved on Day39. However, minimal residual disease (MRD) was positive with both real-time quantitative PCR of KMT2A-AFF1 fusion transcript (11\% of $A B L$ reference gene) and allele specific real-time quantitative PCR of immunoglobulin heavy chain (IGH) gene rearrangement $\left(10^{-2}\right.$ relative to the diagnostic sample). Accordingly, the ALL was considered at very high risk and an ASCT was planned. Despite two high dose cytarabine and methotrexate consolidation chemotherapies [3], the response remained insufficient with positive MRD on Day82 (KMT2A-AFF1: 2.67\%). Blinatumomab (15 mcg/ $\mathrm{m} 2 / \mathrm{d}$ ) was started as a bridge to ASCT from an HLAidentical sibling donor. Despite 3 cycles of blinatumomab, pre-transplantation $\mathrm{MRD}$, an independent major risk of relapse [4], remained unfavorable (KMT2A-AFF1 0.012\% and IGH $10^{-3}$ ). ASCT was performed on Day203 after a myeloablative conditioning (total body irradiation, cyclophosphamide, and etoposide) without T-cell depletion. Post-transplant MRD was undetectable for a year. Unfortunately, MRD became positive at Day582 (IGH $7 \times 10^{-4}$ ) (Fig. 1). Despite one cycle of blinatumomab followed by donor lymphocyte infusion (DLI), MRD progressively increased, without additional genetic mutations. The B-ALL escaped the blinatumomab monotherapy following the loss of CD19 expression by lymphoblasts (Fig. 2.1). Despite FLAG-Ida salvage therapy, and two additional DLIs, ALL relapsed 5 months later (IgH MRD: $7 \times 10^{-1}$ and KMT2A-AFF1 40.6\% on Day826; DNA microarray identified the deletion of 11q23.3q23.3 involving KMT2A gene with a frequency of $80 \%$ and KMT2A rearrangement was detected by FISH at the frequency of $47 \%$ ). At that time,

Minimal Residual Disease

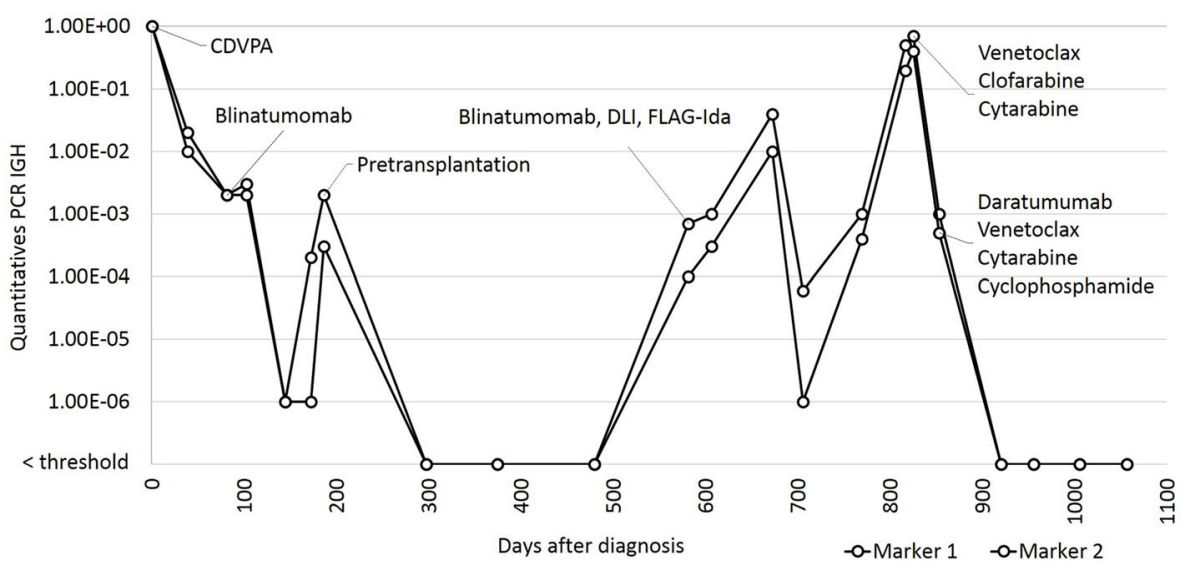

Minimal Residual Disease

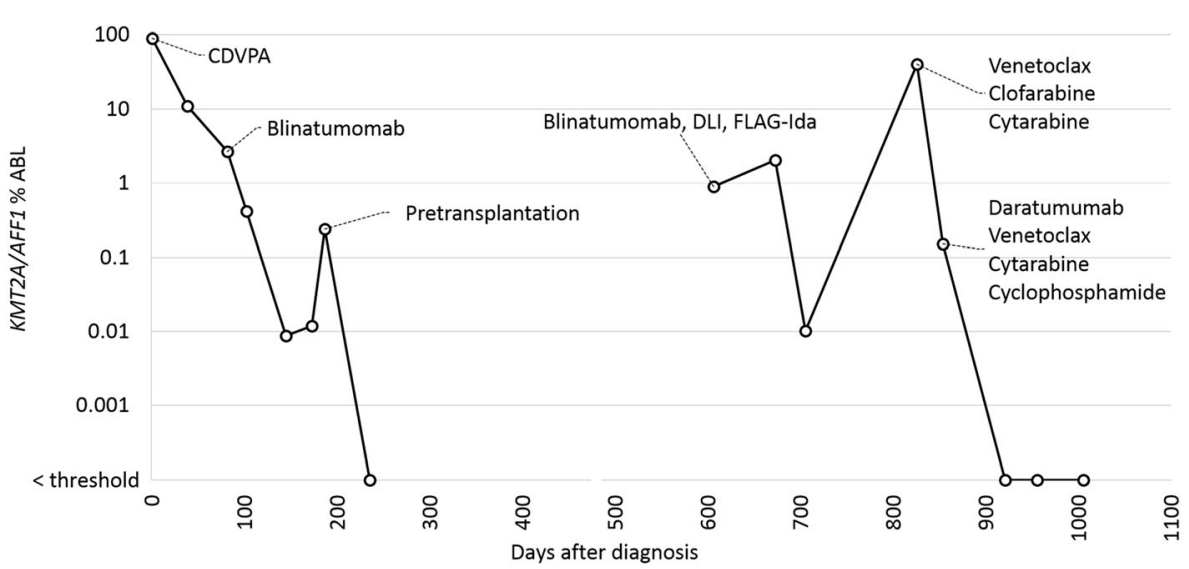

Fig. 1 Minimal Residual Disease measured by real-time quantitative PCR: allele specific of immunoglobulin heavy chain (IGH) gene rearrangement (two distinct markers) and (below) : KMT2A/AFF1 fusion transcript (\% of ABL reference gene). CDVPA : cyclophosphamide, daunorubicin, vincristine, prednisone, asparaginase. 

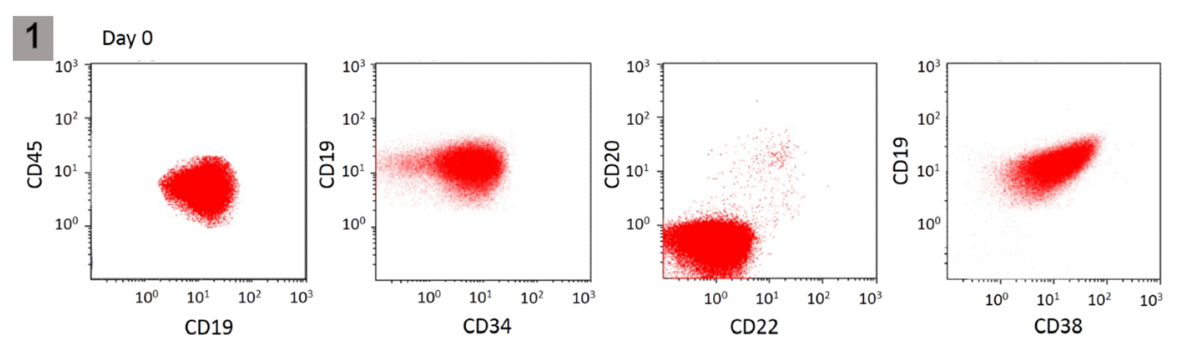

Day 826
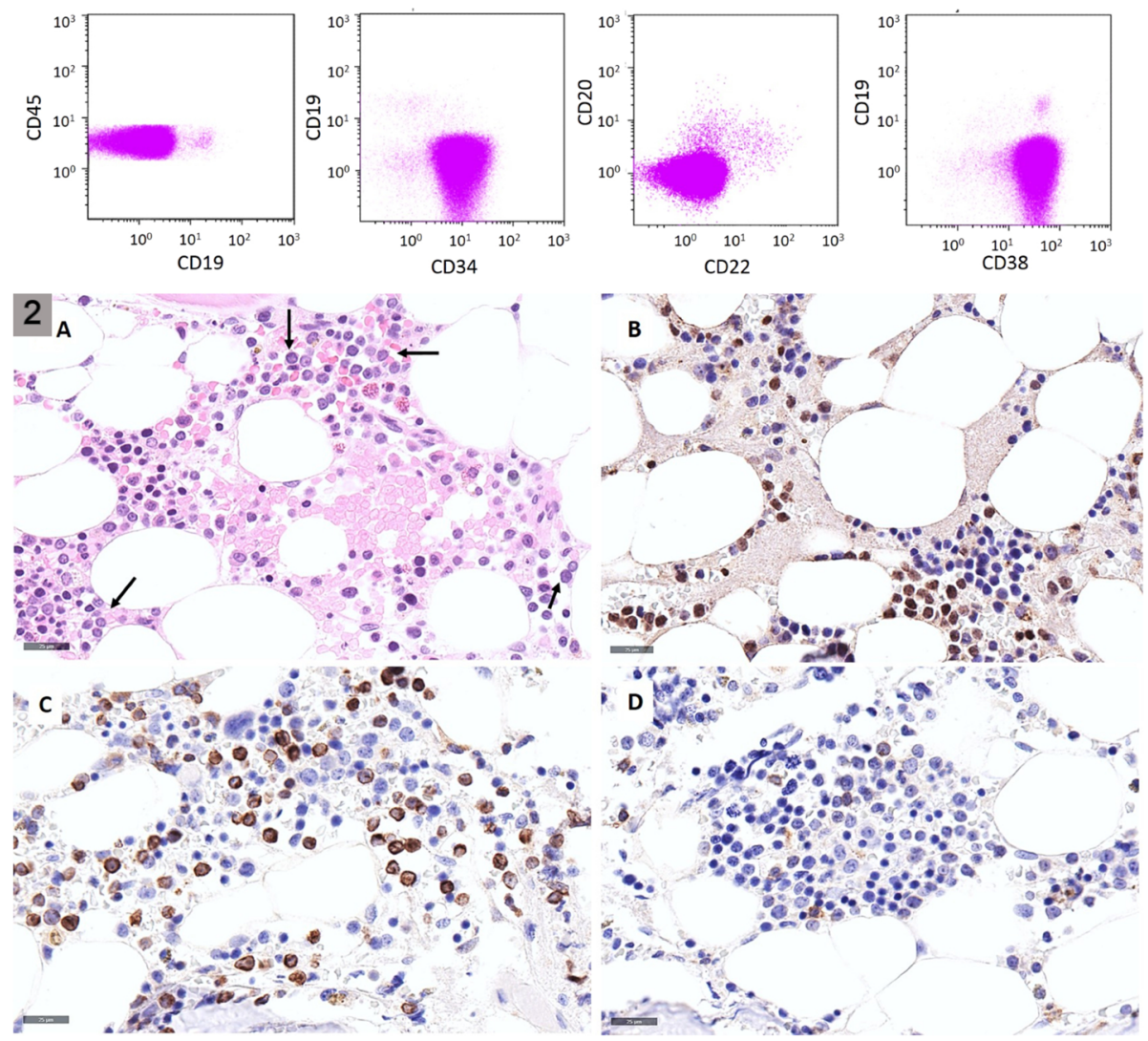

Fig. 2 1) Flow cytometry analysis on Day0 showing blasts cells, gated on CD45/side scatter display, are positive for CD19 and CD38 and negative for CD20 and CD22. On Day826, at relapse and after the exposure to blinatumomab, blasts cells have become negative for CD19. 2) Bone marrow biopsy on D826: the bone marrow contained an interstitial infiltrate of blastic cells (arrows) (A), which were positive for PAX5 (B), BCL2 (C) while only a minority were faintly positive for CD19 (D).

the blast cell immunophenotype was as follow: CD19-, CD200+, CD10-, CD20-, CD38+, CD22-, CD81+, CD34+, CD117-.

In the absence of $\mathrm{CD} 19, \mathrm{CD} 20$, and $\mathrm{CD} 22$ expression by lymphoblasts, treatment options were scarce in this young adult with ECOG 0 performance status. During stem cell donor search, the patient received clofarabine $20 \mathrm{mg} / \mathrm{m}^{2} / \mathrm{d}$ and cytarabine $1000 \mathrm{mg} / \mathrm{m}^{2} / \mathrm{d}$ for 5 days with venetoclax $400 \mathrm{mg} / \mathrm{d}$ (Day1-13), as blasts expressed BCL-2 (Fig. 2.2) and as venetoclax efficacy was reported in pediatric BALL models with MLL rearrangements [5, 6]. At Day28, morphologic CR was achieved; however, MRD remained positive (IgH: $10^{-3}$; KMT2A-AFF1: 0.15\%).
Considering the potential efficacy of daratumumab in R/R ALL [7-10] and the expression, by lymphoblasts, of high CD38 levels, a therapy targeting both BCL-2 (venetoclax $100 \mathrm{mg}$, Day3-7) and CD38 (daratumumab, $16 \mathrm{mg} / \mathrm{kg}$, on Day2 and Day10) was administered with cyclophosphamide (150 mg/m $\mathrm{m}^{2}$ bid Day1-3) and clofarabine $(20 \mathrm{mg} / \mathrm{m} 2$ Day1-5) to achieve molecular CR. Prolonged agranulocytosis (43 days) was induced with complete hematopoietic reconstitution and molecular CR achieved (sensitivity $:<0.003 \% A B L$ and $<10^{-4}$ or $10^{-5}$ for $I G H$ rearrangement depending on the marker). MRD remained undetectable during the 5-month delay between the hematopoietic reconstitution and the 
second ASCT, with a matched unrelated donor. Twelve months post-ASCT, the patient is in molecular CR under venetoclax maintenance with full donor chimerism.

This case illustrates a successful salvage therapy for a very high-risk R/R KMT2A-AFF1 positive B-ALL, expressing CD38 and BCL-2, but negative for CD19, CD20, and CD22. To overcome chemoresistance, we chose to combine chemotherapy with the BCL-2 inhibitor venetoclax to promote the apoptosis of both lymphoblasts and immature KMT2A-mutated leukemia, which may switch to a myeloid phenotype [11]. In order to achieve a deep and sustained molecular remission before ASCT, venetoclax was then combined with the anti-CD38 monoclonal antibody daratumumab, which can induce cell apoptosis via antibody- and complement-dependent cellular cytotoxicity and promote antibody-dependent cellular phagocytosis [12]. Considering the early relapse after FLAG-Ida salvage chemotherapy, the failure to achieve molecular CR with the cyclophosphamide-including induction therapy, and a salvage regimen containing clofarabine and cytarabine; daratumumab and venetoclax most likely played a major role in obtaining the complete molecular response with an undetectable MRD. This hypothesis is further supported by results of ongoing clinical trials and case reports, which show that venetoclax [13] and/or daratumumab [7-10], can eradicate MRD in R/R B-ALL or highrisk T-ALL. This case highlights the importance of the sequential assessment of immunotherapeutic target at the surface of lymphoblasts during the course of treatment, and of the potential role of targeting BCL-2 and CD38 antigen in R/R B-ALL, in particular after CD19 antigen loss following CD19-targeted immunotherapies.

\section{Abbreviations}

R/R: relapsed/refractory; B-ALL: B-cell acute lymphoblastic leukemia; ASCT: allogeneic hematopoietic stem cell transplantation; PCR: Polymerase chain reaction; CR: complete remission; MRD: minimal residual disease; IGH: immunoglobulin heavy chain; DLI: donor lymphocyte infusion

\section{Supplementary information}

The online version contains supplementary material available at https://doi. org/10.1186/s40364-021-00343-3.

Additional file 1: Supplementary material. Bone marrow aspiration at diagnosis $(A+B)$, first relapse (Day $673 ; C+D)$ and second relapse (Day 826; E+F). MGG staining $\times 100(\mathbf{A}, \mathbf{C}, \mathbf{E})$ and $\times 400(\mathbf{B}, \mathbf{D}, \mathbf{F})$.

\section{Acknowledgements}

With thanks to Valentin Basset for the flow cytometry analysis and for providing part of the figures and to Jeanette Carr Klappert for her careful English review.

\section{Authors' contributions}

SV, SB and OS were in charge of the patient, did the literature review and wrote the manuscript. LdL performed the analyses of the bone marrow. JS and FS performed the genetic and molecular analyses. All authors read and approved the final manuscript.
Funding

None.

Availability of data and materials

Not applicable.

\section{Declarations}

Ethics approval and consent to participate

Not applicable.

\section{Consent for publication}

The patient gave his written consent to this publication.

\section{Competing interests}

The authors report no conflicts of interest in this work.

\section{Author details}

${ }^{1}$ Service and Central Laboratory of Hematology, Lausanne University Hospital (CHUV), Lausanne, Switzerland. ${ }^{2}$ Service and Central Laboratory of Hematology, Centre Hospitalier Universitaire Vaudois and University of Lausanne, CH-1011 Lausanne, Switzerland. ' 3 Lausanne University (UNIL), Lausanne, Switzerland. ${ }^{4}$ Institute of Pathology, Department of Laboratory Medicine and Pathology, Lausanne University Hospital and Lausanne University, Lausanne, Switzerland. ${ }^{5}$ Oncogenomics laboratory, Lausanne University Hospital (CHUV), Lausanne, Switzerland.

Received: 8 October 2021 Accepted: 23 November 2021

Published online: 20 December 2021

\section{References}

1. Gökbuget N, Stanze D, Beck J, et al. Outcome of relapsed adult lymphoblastic leukemia depends on response to salvage chemotherapy, prognostic factors, and performance of stem cell transplantation. Blood. 2012;120:2032-2041

2. Kantarjian $\mathrm{H}$, Stein $\mathrm{A}$, Gokbuget $\mathrm{N}$, et al. Blinatumomab versus chemotherapy for advanced acute lymphoblastic leukemia. N Engl J Med. 2017:376:836-847.

3. Faderl S, Thomas DA, O'Brien S, Ravandi F, Garcia-Manero G, Borthakur G, Ferrajoli A, Verstovsek S, Ayoubi M, Rytting M, Feliu J, Kantarjian HM. Augmented hyper-CVAD based on dose-intensified vincristine, dexamethasone, and asparaginase in adult acute lymphoblastic leukemia salvage therapy. Clin Lymphoma Myeloma Leuk. 2011;11:54-9.

4. Berry DA, Zhou S, Higley $\mathrm{H}$, et al. Association of minimal residual disease with clinical outcome in pediatric and adult acute lymphoblastic leukemia: a metaanalysis. JAMA Oncol. 2017;3.

5. Benito JM, Godfrey L, Kojima K, et al. MLL-rearranged acute lymphoblastic leukemias activate BCL-2 through H3K79 methylation and are sensitive to the BCL-2-specific antagonist ABT-199. Cell Rep. 2015;13:2715-2727.

6. Khaw SL, Suryani S, Evans K, Richmond J, Robbins A, Kurmasheva RT, Billups CA, Erickson SW, Guo Y, Houghton PJ, Smith MA, Carol H, Roberts AW, Huang DCS, Lock RB. Venetoclax responses of pediatric ALL xenografts reveal sensitivity of MLL-rearranged leukemia. Blood. 2016 Sep 8;128(10): 1382-95. doi: https://doi.org/10.1182/blood-2016-03-707414. PMID: 27343252

7. Daratumumab at the frontiers of post-transplant refractory T-acute lymphoblastic leukemia-a worthwhile strategy? Bonda A, Punatar S, Gokarn A, Mohite A, Shanmugam K, Nayak L, Bopanna M, Cheriyalinkal Parambil B, Khattry N. Bone Marrow Transplant. 2018 Nov;53(11):1487-1489. doi: https:// doi.org/10.1038/s41409-018-0222-5. Epub 2018 Jun 8. PMID: 29884853

8. Immunomodulatory and clinical effects of daratumumab in T-cell acute lymphoblastic leukaemia. Cerrano M, Castella B, Lia G, Olivi M, Faraci DG, Butera S, Martella F, Scaldaferri M, Cattel F, Boccadoro M, Massaia M, Ferrero D, Bruno B, Giaccone L. Br J Haematol. 2020 191(1):e28-e32. doi: https://doi. org/10.1111/bjh.16960. Epub 2020 Jul 19. PMID: 32686081

9. Daratumumab for eradication of minimal residual disease in high-risk advanced relapse of T-cell/CD19/CD22-negative acute lymphoblastic leukemia. Ofran Y, Ringelstein-Harlev S, Slouzkey I, Zuckerman T, YehudaiOfir D, Henig I, Beyar-Katz O, Hayun M, Frisch A. Leukemia. 2020;34(1):293295. doi: https://doi.org/10.1038/s41375-019-0548-z. Epub 2019 Aug 21. PMID: 31435023 
10. Daratumumab for quick and sustained remission in post-transplant relapsed/refractory acute lymphoblastic leukemia. Zhang Y, Xue S, Liu F, Wang J. Leuk Res. 2020;91:106332. doi: https://doi.org/10.1016/j.leukres.202 0.106332. Epub 2020 Feb 24. PMID: 32126433

11. Haddox CL, Mangaonkar AA, Chen D, Shi M, He R, Oliveira JL, Litzow MR, AlKali A, Hogan WJ, Elliott MA. Blinatumomab-induced lineage switch of BALL with t(4:11)(q21;q23) KMT2A/AFF1 into an aggressive AML: pre- and post-switch phenotypic, cytogenetic and molecular analysis. Blood Cancer J. 2017;7(9):e607.

12. Sanchez L, Wang Y, Siegel DS, Wang ML. Daratumumab: A first-in-class CD38 monoclonal antibody for the treatment of multiple myeloma. J Hematol Oncol. 2016;9(1):51. Doi: https://doi.org/10.1186/s13045-016-0283-0

13. Jain N, Stevenson KE, Winer ES, et al. A multicenter phase I study combining venetoclax with mini-hyper-CVD in older adults with untreated and relapsed/refractory acute lymphoblastic leukemia. Blood. 2019. 134 (suppl 1; abstr 3867).

\section{Publisher's Note}

Springer Nature remains neutral with regard to jurisdictional claims in published maps and institutional affiliations.

Ready to submit your research? Choose BMC and benefit from:

- fast, convenient online submission

- thorough peer review by experienced researchers in your field

- rapid publication on acceptance

- support for research data, including large and complex data types

- gold Open Access which fosters wider collaboration and increased citations

- maximum visibility for your research: over $100 \mathrm{M}$ website views per year

At BMC, research is always in progress.

Learn more biomedcentral.com/submissions 